\title{
Le théâtre de Rotrou, sous la direction de Pierre Pasquier
}

Daniela Dalla Valle

\section{(2) OpenEdition}

1 Journals

\section{Edizione digitale}

URL: http://journals.openedition.org/studifrancesi/8899

DOI: 10.4000/studifrancesi.8899

ISSN: 2421-5856

\section{Editore}

Rosenberg \& Sellier

\section{Edizione cartacea}

Data di pubblicazione: 1 octobre 2008

Paginazione: 449-450

ISSN: 0039-2944

\section{Notizia bibliografica digitale}

Daniela Dalla Valle, «Le théâtre de Rotrou, sous la direction de Pierre Pasquier», Studi Francesi [Online],

155 (LII | II) | 2008, online dal 30 novembre 2015, consultato il 13 janvier 2021. URL: http://

journals.openedition.org/studifrancesi/8899; DOl: https://doi.org/10.4000/studifrancesi.8899

Questo documento è stato generato automaticamente il 13 janvier 2021.

\section{(c) (i) (9)}

Studi Francesi è distribuita con Licenza Creative Commons Attribuzione - Non commerciale - Non opere derivate 4.0 Internazionale. 


\title{
Le théâtre de Rotrou, sous la direction de Pierre Pasquier
}

\author{
Daniela Dalla Valle
}

\section{NOTIZIA}

Le théâtre de Rotrou, sous la direction de Pierre PASQUIER, «Littératures classiques», 63, automne 2007, pp. 325.

1 Questo fascicolo di «Littératures classiques» si propone di accompagnare la ripubblicazione del teatro di Rotrou, iniziata alcuni anni fa e la cui conclusione si prevede per il 2011, nella Société des Textes Français Modernes. Pierre PASQUIER, che presenta i ventuno articoli inseriti nel volume, sottolinea l'interesse di questo nuovo approccio a Rotrou, sia rispetto al libro fondamentale di Jacques Morel, sia rispetto ai volumi successivi di Jacqueline Van Baelen, di Jacques Scherer (nei passaggi inseriti nel suo Théâtre du xviie siècle), o di Jean-Claude Vuillemin. Ci spiace, purtroppo, che in questo rapido percorso dato agli studi rotrouiani non sia stato lasciato spazio al volume di Francesco Orlando, Rotrou: dalla tragicommedia alla tragedia, uscito addirittura prima del volume di Jacques Morel.

Gli articoli inseriti in questo numero di «Littératures classiques» sono stati raggruppati ed inseriti in sette settori. Il primo settore, «Un homme de son temps», comprende un unico articolo, quello di A. RIFFAUD, Jean Rotrou et ses livres, che ci offre un'analisi estremamente precisa e puntigliosa delle varie edizioni delle pièces rotrouiane. Il secondo settore, «En adaptant la 'comedia'", comprende due articoli che s'interrogano sul rapporto fra Rotrou e la comedia spagnola: uno di L. PICciola (Rotrou et le traitement comique du déguisement à l'espagnole) e uno di c. DUMAs (Rotrou adaptateur de Lope de Vega). Il terzo settore, «Une pratique singulière des genres», porta il discorso sull'uso dei generi teatrali e sull'originalità di Rotrou in questo campo. B. LOUVAT-MOLOZAY ( $\mathrm{La}$ tragédie de Rotrou au carrefour des genres dramatiques) sottolinea come nella pratica teatrale di Rotrou la tragedia e la tragicommedia si mescolino spesso; H. BABY (Le capitan 
dans la comédie et dans la tragi-comédie française) si sofferma su un particolare personaggio del teatro di Rotrou, confrontato con altre versioni nel teatro francese contemporaneo; P. ScoTt (Rotrou et la comédie de dévotion) evidenzia i riferimenti liturgici nel Véritable Saint Genest, all'interno di un genere relativamente diffuso negli anni Quaranta; S. BERREGARD (La mixité des genres dramatiques dan le théâtre de Rotrou) sottolinea il modo in cui Rotrou non separa mai completamente i vari generi teatrali che pratica; A. TEULADE (Inventivité générique et réception de la 'comedia' espagnole dans "Bélisaire" et "Venceslas") ritorna sul rapporto con la comedia spagnola per sottolineare la scelta di formule tragiche inedite. Due soli articoli sono inseriti nel settore IV: «Une écriture». D. MONCOND'HUY (Remarques sur la pratique du vers dans le théâtre grave de Rotrou) si occupa della pratica della versificazione, e R. GARRETTE (De la ponctuation à l'analyse de la phrase), confrontando l'Iphigénie di Rotrou con quella di Racine, sottolinea la grande differenza stilistica tra l'una e l'altra, in una sorta di "stylométrie comparée". Più ricco di articoli è il V settore, «Une dramaturgie pour la scène». Sei articoli si soffermano a identificare, attraverso le didascalie, una certa regia dello spettacolo (V. LOCHERT, Rotrou entre les lignes); oppure, analizzando i personaggi del tutto secondari, giungono a definire un certo aspetto del teatro di Rotrou (N. COURTÈs, La mimésis du silence: figurants et petits rôles dans le théâtre de Rotrou); sottolineano, inoltre, come la drammaturgia di Rotrou sia stata concepita secondo la funzione degli obblighi scenici (P. GETHNER, Une dramaturgie conçue en fonctions des contraintes de la scène); si occupano poi degli abiti "alla romana" nel Véritable Saint Genest, per sottolineare il rapporto fra l'antichità e la realtà scenica (A. VERDIER e D. DOUMERGUE, Distance antique et réalité scénique en 1646); infine analizzano il monologo come convenzione barocca (c. THOURET, Le monologue dans le théâtre de Rotrou), e si soffermano sulla rappresentazione del re, e sul modo in cui Rotrou lo rappresenta sulla scena (c. TREILHOU-BALAUDÉ, Rotrou poète de la scène). Il settore VI, «Le théâtre d'une épistémologie», s'interessa piuttosto al teatro come espressione delle caratteristiche filosofiche dell'epoca, caratterizzata - secondo J.c. vuILLEMAIN (Jeux de théâtre et enjeux du regard) - dalla drammaturgia barocca, intesa come un certo modo di concepire il mondo e - secondo A. SURGERS (Que voit-on sur le théâtre?) - da quanto la scena mostra, attraverso le entrate e le uscite di scena. L'ultimo settore, il settimo, è dedicato invece alle Réceptions d'un théâtre: M. BÉTHERY ("Venceslas revu par Marmontel") si occupa della riscrittura di Venceslas, fatta da Marmontel nel 1759; E. MORGAT-LONGUET (Images de Rotrou dans l'historiographie du théâtre français) si sofferma sulle immagini date di Rotrou nella storiografia del teatro francese tra il 1674 e il 1750; infine M. Baschera (Qu'est-ce que "Le Véritable Saint Genest" peut nous apprendre aujourd'hui) s'interroga sul senso attuale del Véritable Saint Genest.

Il numero è molto ricco, i punti di approccio al testo rotrouiano sono svariati e spesso interessanti; la riedizione moderna del teatro di Rotrou ha evidentemente arricchito la sua bibliografia critica, e certamente continuerà a stimolare approcci diversi. 